This is a paper published in Environmental Practice. This paper has been peer-reviewed and includes the final publisher proof-corrections and journal pagination.

Citation for the published paper:

Skärbäck, E. (2007) Landscape planning to promote well-being: studies and examples from Sweden. Environmental Practice. Volume: 9

Number: 3, pp 206 - 217.

http://dx.doi.org/10.1017/S1466046607070299

Access to the published version may require journal subscription.

Published with permission from: Cambridge University Press.

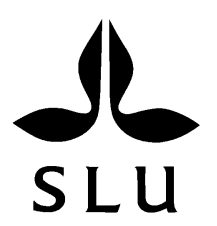

Epsilon Open Archive http://epsilon.slu.se 


\section{Landscape Planning to Promote Well Being: Studies and Examples from Sweden}

\section{Erik Skärbäck}

There has been a rapid increase in knowledge regarding the importance of the external environment to our health. Eight characteristics of the outdoor environment (serene, wild, lush, spacious, the common, the pleasure garden, festive/ centre, and culture) have been identified as fulfilling recreational needs through a number of environmental psychology studies carried out at the Swedish University of Agricultural Sciences, Alnarp, Sweden, between 1995 and 2005. The external environment has become an increasingly decisive factor in people's choices regarding where to live and work; the landscape has become a competitive factor in attempts made by companies and local authorities to attract well-educated, mobile manpower and housing. Knowledge-based companies predominate in the Öresund Region of Sweden and Denmark, which at present has substantial recreational values making it an attractive area in which to live and work. The region's annual population growth is approximately 20,000 to 25,000 inhabitants. The prime ministers of Sweden and Denmark have expressed a common objective that the Öresund Region be one of Europe's cleanest metropolitan regions. The objective of this article is to present methods for implementing the eight characteristics as indicators for impact assessment in planning projects. The article presents case studies of the application of environmental impact assessments in the municipalities of Malmö and Svedala, which are situated in the immediate vicinity of the Öresund Bridge. Development plans are being evaluated through impact assessment. Mitigation and compensation measures are being created to achieve the environmental quality goals defined by the eight characteristics. The case studies referred to in this article are in very early planning phases, either the feasibility or pre-feasibility phase. This article does not present complete investigations of balancing, but discusses some principal ways of defining values and suggests measures for mitigating and compensating for negative impacts on existing values.

Environmental Practice 9:206-217 (2007)

G reen areas and parks with certain qualities and low noise disturbance meet important demands for stress reduction (Grahn, Stigsdotter, and Berggren-Bärring, 2005a). Peace and quiet are positive resources for an individual's perception of his/her surroundings; sounds of nature restore people from mental fatigue (Kaplan and Kaplan, 1989). Inversely, a lack of green areas and parks in neighborhoods, as well as high levels of noise, increases the risk of developing stress-related illnesses (Babisch et al., 2005; Grahn and Stigsdotter, 2003). The development of eight characteristics of significant importance for people's health and well being (Grahn, Stigsdotter, and Berggren-Bärring, 2005a, 2005b) improves our ability to strengthen the aspect of recreation in impact assessment processes.

Historical master planning of cities has focused on the interaction between built areas and open space areas. The "Fingerplan" of Copenhagen from 1947 (Caspersen, Konijnendijk, and Olafsson, 2006) is an example in which the city of Copenhagen is supposed to grow like a hand, with peripheral growth like fingers along transport corridors, and with the space between the fingers for green areas. The twentieth century seems to demonstrate a tendency in which educated people search for good places to live for themselves and their children and in which employers have to follow. When California's Silicon Valley was established, localization factors such as beautiful land-

Affiliation of author: Department of Landscape Planning, Swedish University of Agricultural Sciences, Alnarp, Sweden

Address correspondence to: Erik Skärbäck, Professor in Regional Planning, Department of Landscape Planning, Swedish University of Agricultural Sciences, 23053 Alnarp, Sweden; (e-mail) Erik.Skarback@ltj.slu.se.

(c) 2007 National Association of Environmental Professionals 
scapes and good recreation facilities were important from the outset, as were good opportunities for making contact with other companies. At present, Silicon Valley is overcrowded and we can see how new knowledge-based business parks are being established in new and lovely landscaped areas such as Portland, Oregon. This new trend seems to be most significant for knowledge-based industries.

The practical implementation of green qualities constitutes a major challenge for planners, researchers, and stakeholders within the Öresund Region of Sweden and Denmark. This challenge is particularly demanding owing to the many contrasting interests and the high development rate. In fact, the region is developing at a speed that at times exceeds traditional planning procedures. The region holds large potentials in terms of its green areas and amenity values. Moreover, the educational level of the population helps to create favorable conditions for high-tech industries. Despite the large potentials of the region, the rapid development may deteriorate green areas and amenity values, thus reducing the region's general qualities.

A collaborative research program, "Landscape as a Resource for Health and Development in the Öresund Sound Region," is being conducted by the Department of Landscape Planning at the Swedish University of Agricultural Sciences (SLU) in Alnarp and by universities in Zeeland, Denmark. The program operates in the fields of environmental psychology, planning, and public health. It attempts to meet the challenge of creating planning tools that enable development of the Öresund Region with due respect to the richly faceted interests represented. The program is designed to be both research- and action-oriented and includes cooperation between scientists and private and public bodies; this structure will ensure the practical relevance and operability of research outcomes. This article presents two case studies from the research program, carried out by the research group at SLU. One case study regards the development of housing on previous industrial sites, and the other concerns the extension of infrastructure in attractive landscapes frequently used for outdoor recreation.

Several investigations show that people are often afflicted by illnesses related to stress (Grahn and Stigsdotter, 2003; Ottosson and Grahn, 2005a, 2005b; Ottosson and Grahn, 2006). Recent investigations have shown a relationship between urban green areas and good health (Hartig et al., 1996; Ottosson and Grahn, 1998). Hartig (1993) has shown that blood pressure drops after walking in a natural environment for a few minutes. Stays in green areas have been shown to result in relaxation effects and improved concentration. Light and open environments, such as Swedish grazing lands or older, well-established parks (particularly those with water elements) have been shown to rapidly trigger positive feelings. This may be explained by the fact that such biotopes and habitats have been of great importance during human evolution (Cross, 1991; Ulrich, 1993). In pressed situations, when people are stressed or ailing, it is of even more importance that such environments be available. If people can find places such as these, blood pressure and pulse (for example) can return to normal more quickly (Ottosson and Grahn, 1998).

Parsons et al. (1998) have studied differences in stress levels between those who commute from home to work by passing through an attractive landscape and those who commute via an industrial road environment; even short "relaxing" views (called "micro-pauses") have been shown to have positive health effects. One hypothesis is that the emergence of creative, innovative environments is facilitated by frequent opportunities for recreational experiences of "non-demanding" natural elements, e.g., water, stones, earth, plants, and animals (Searles, 1960).

The brain's capacity to deal with large amounts of information in higher consciousness, through the Directed Attention System (DAS), is highly limited (Kaplan and Kaplan, 1989). It has been postulated that human attention consists of two types of attention. One, Directed Attention, is located in the higher cognitive centers and deals with the processing of impressions such as office work, driving a car in traffic, etc.-activities requiring a great deal of mental energy (Kaplan, 1990). The other type, Involuntary Attention, is located in the limbic system and brain stem and is used, e.g., to identify rustling in a bush, a butterfly flying over a meadow, etc. - activities requiring very little mental energy. Prolonged and high workloads and stress drain the capacity of the DAS, which often leads to burnout. Burnout, in turn, leads not only to personal tragedies, but also to long and costly rehabilitation programs (Kaplan, Kaplan, and Ryan, 1998).

Information taken in via our vision, hearing, sense of touch, and smell is largely processed subconsciously, likely partly in accordance with innate genetic memory functions from millions of years of human evolution (Cross, 1991). Stays in green environments seem to facilitate the processing of information in higher consciousness; thus, such stays may help to prevent burnout caused by prolonged and high workloads and stress. City planning that fails to appropriately integrate green spaces into work, housing, and every- 
day environments will likely result in lower productivity, poorer public health, and associated increases in social expenditures.

Some studies reveal the importance of having a park very close to home (Grahn and Stigsdotter, 2003). Individuals who visit green areas seem to recover more rapidly from stress-related afflictions (Ulrich et al., 1991). Green infrastructure in cities provides substantial goods and services for modern society, some of them ecological or environmental (Boverket, 1994; Nilsson, Konijnendijk, and Randrup, 1999), such as habitat functions and retreat for plants and wildlife (Scott, McPherson, and Simpson, 1998). Knowledge regarding the optimum size, shape, and function of urban green areas with respect to human welfare and biodiversity is still scarce, however.

An attractive environment with respect to noise and sound may be beneficial for health and well being, also. A number of landscape architecture and environmental psychology studies conducted via interview in different parts of Sweden between 1995 and 2005 have revealed eight characteristics of the outdoor environment-serene, wild, lush, spacious, the common, the pleasure garden, festive/centre, and culture-corresponding to basic human needs (Grahn et al., 2005b). Per Hedfors (2003) has discussed how these eight characteristics include the important component of sound, reporting on both positive (euphony, music) and negative (noise, commotion) elements. Ulrika Stigsdotter (2005a, 2005b) has focused her doctoral thesis, "Landscape Architecture and Health," on-among other things - the use of urban green spaces and city planning to promote health. The eight characteristics said to meet recreational needs also are described by Stigsdotter and Grahn (2002) and can be summarized as categories of certain closely related values in a Swedish context; note that this corresponds to the preferences of people interviewed in Sweden:

1. Serene: A place of peace, silence, and care; sounds of wind, water, birds and insects; no rubbish, no weeds, no disturbing people.

2. Wild: A place of fascination with wild nature; plants seem self-sown; lichen and moss-grown rocks, old paths.

3. Lush: A place rich in species; a room offering a variety of wild species of animals and plants.

4. Spacious: A room offering a restful feeling of "entering another world"; a coherent whole, like a beech forest.

5. The common: A green, open place allowing vistas and stays.
6. The pleasure garden: A place of imagination; an enclosed, safe, and secluded place where one can relax and be oneself; children play freely.

7. Festive/centre: A meeting place for festivity and pleasure.

8. Culture: The essence of human culture; a historical place offering fascination with the course of time.

Some of the characteristics (value categories) seem very similar and there are often discussions of how those characteristics corresponding to basic human needs ought to be translated and implemented in actual practice, in projects with different preconditions. In the program, "Landscape as a Resource for Health and Development in the Öresund Sound Region," the discussions come from two directions: academic researchers, who take a theoretical point of view, and the municipal staff implementing the theories in practice, who take a methodological point of view.

A large-scale (25,00o persons) study of the region of Skåne in southern Sweden showed that natural neighborhood environments, assessed using objective geographic information system measures of five of the eight characteristics, promoted neighborhood comfort and physical activity and seemed, to some extent, to prevent obesity in suburban and rural areas. The study results (submitted for publication elsewhere) highlight the crucial importance of highquality, natural surroundings for apartment tenants in particular, most of whom have no access to a garden of their own.

Although it has not been studied, it is highly likely that people from other countries also require serenity, wilderness, biodiversity, space, etc., but the types of landscapes to which these characteristics correspond will certainly be different for people from, e.g., southern Europe, Africa, Ecuador, or New York. Thus, the definitions of such characteristics will certainly vary from culture to culture. Defining these characteristics across different cultures will pose a challenge to landscape analysts studying landscapecharacteristic correspondences to people's preferences. To serve such a purpose, a Web-based method has been developed by the faculty at Alnarp (Östlund, 2006).

\section{Methods}

Evaluation of the eight characteristics before and after a planned development project constitutes a main thread throughout the cases studied. As mentioned, the impact analysis in this project focused on consequences for health 
values, not primarily on ecological aspects. Measures for mitigating and compensating for negative, unavoidable impacts-"balancing"- were discussed in the case studies. Balancing lack of expected characteristics has been accomplished using two different approaches: (1) suggestions for restoration and compensation measures in a pre-investigation phase for the permit application, and (2) "green factor analysis," integrated into the concept phase of the development planning.

\section{Balancing}

The "balancing method" refers to the use of compensation measures. Environmental compensation is one way to restore and recover damaged ecosystems and to deal with human exploitation. Such measures are economically beneficial and enable people to have closer relationships with nature and culture (Clewell, 200o). The value of ecosystem services and natural capital stocks was estimated at approximately 33 trillion US\$ per year for the entire globe in 1997 (Costanza et al., 1997).

Compensation measures have been used in Germany (Berlin) since 1976, before environmental impact assessment was established in Germany. They then became a part of the German Environmental Act and are now also a part of the German Building Act. Use of environmental compensation in Germany, the US, the Netherlands, the UK, and Sweden has been studied by Rundcrantz and Skärbäck (2003). The review shows that all of the studied countries focus on ecological values, but that in the UK there is also a focus on landscape scenery and amenity values. In addition, the review shows that legislation is strong in Germany and the US and to some extent in the Netherlands, but unclear in the UK and Sweden. In Sweden, there is no special legislation except some paragraphs in the Environmental Code and regulations for roads, despite the fact that environmental compensation is increasing in, e.g., Swedish road planning (Rundcrantz, 2006). What we hopefully can provide in the "Landscape as a Resource" program is a stronger focus on values for health and recreation. In Sweden, the balancing method has been under development at the university level since the mid-199os (Skärbäck, 1997).

\section{Green Factor}

The balancing method is not sufficient to ensure a satisfactory environmental standard in a development area. Especially in situations where the existing values at the outset are more limited than the future demands for the development (e.g., former industrial sites), there may be a need for defining a minimum standard of biotope qualities. Authorities may establish a "green factor" that can be used as a condition for granting a building permit. The method is normally implemented in the design phase at the block level, and when well used can be an inspiring precondition for creative architects wishing to integrate nature and culture.

The "green factor" method was originally developed in Germany and is now a regular part of the German Planning Act. Each city plan in Germany is accompanied by a "Grünordnungsplan," which indicates how to take care of existing green areas and defines standards for new green qualities in the planning area. The green factor is an imaginary green area that is divided by the total lot area. The imaginary green area is calculated by multiplying every sub-area (of the total lot) by a factor between 0.1 (paved surfaces) and 1 (fully developed vegetation in deep soil). Planting for, e.g., garage projects with limited soil is not expected to give the same potential for vegetation development as other projects and would thus be assigned a green factor of 0.6 to 0.8 . The sum of all imaginary green spaces makes up the total imaginary green space. By setting an objective for the total imaginary green space, the indicator can be used in relation to the level of possible biodiversity. The authorities establish a minimum average factor for each planning area.

Criteria for classification of each single part are the quality of plantings and the use of the rainwater resource, e.g., streams and ponds, in the area. Green roofs are an example of a measure stimulated by using a green factor. Green roofs not only improve the environment for insects and birds, but also stop about $50 \%$ of the rainwater from immediately running off into pipelines, which is frequently the cause of flooding in risk areas. The goal to slow the water runoff is also aimed at improving the city climate by promoting healthy humidity. In Germany, green roofs are assigned a green factor of 0.7 .

Green factor analysis was first used in Sweden in 2001, at the annual housing exhibition Boo1 in Malmö, although it is not yet required by Swedish law. Use of green factor analysis certainly can improve the quality of a housing area, however; therefore, developers and municipalities are starting to implement the method in their plans for environmental profiling and also for economical reasons. The following cases are preliminary proposals laid out at SLU to show how balancing and green factor analysis can be implemented in concrete development projects at a very 
early planning phase. How they ultimately affect the plans may be a study in its own right.

\section{Case Studies}

\author{
Malmö: Sorgenfri, Converting Industry \\ to Mixed City
}

Sorgenfri is a mixed, small-scale industrial area in the eastern part of central Malmö, Sweden. In the comprehensive plan of the city, this part of Malmö is evaluated as having a shortage of green space areas. The development area is surrounded by a railroad and housing blocks from the early twentieth century. A large cemetery is located in the southwest part of the area. Broad streets cross the area, one with heavy traffic. Embedded in the area is an old hospital park. The buildings vary in style, mostly brick and sheet-metal facades, and the heights vary from mostly one to two stories, although one new six-story office building exists. The area contains considerable amounts of vast open space, but almost no greenery or public space. Besides the industries, the area today hosts a number of artists and some homeless inhabitants.

The study started with an inventory and evaluation of the eight characteristics in each block (Flodmark, 2004). The first analysis dealt with which characteristics would be possible, given the alternative sketches made by the architect commissioned by the city. A rather dense alternative (see Figure 1) resulted in the Lush (3) and Wild (2) qualities being highly reduced, without substantial addition of other green qualities; however, there was an increase in "Festive/ centre" (7). In the upper part of the picture, there are some characteristics of "The common" (5) for vistas and lawn activities, and "Lush" (3) and "Culture" (8) in two already existing housing blocks. "The pleasure garden" (6), "Serene" (1), and "Space" (4) are possible in only one block. The

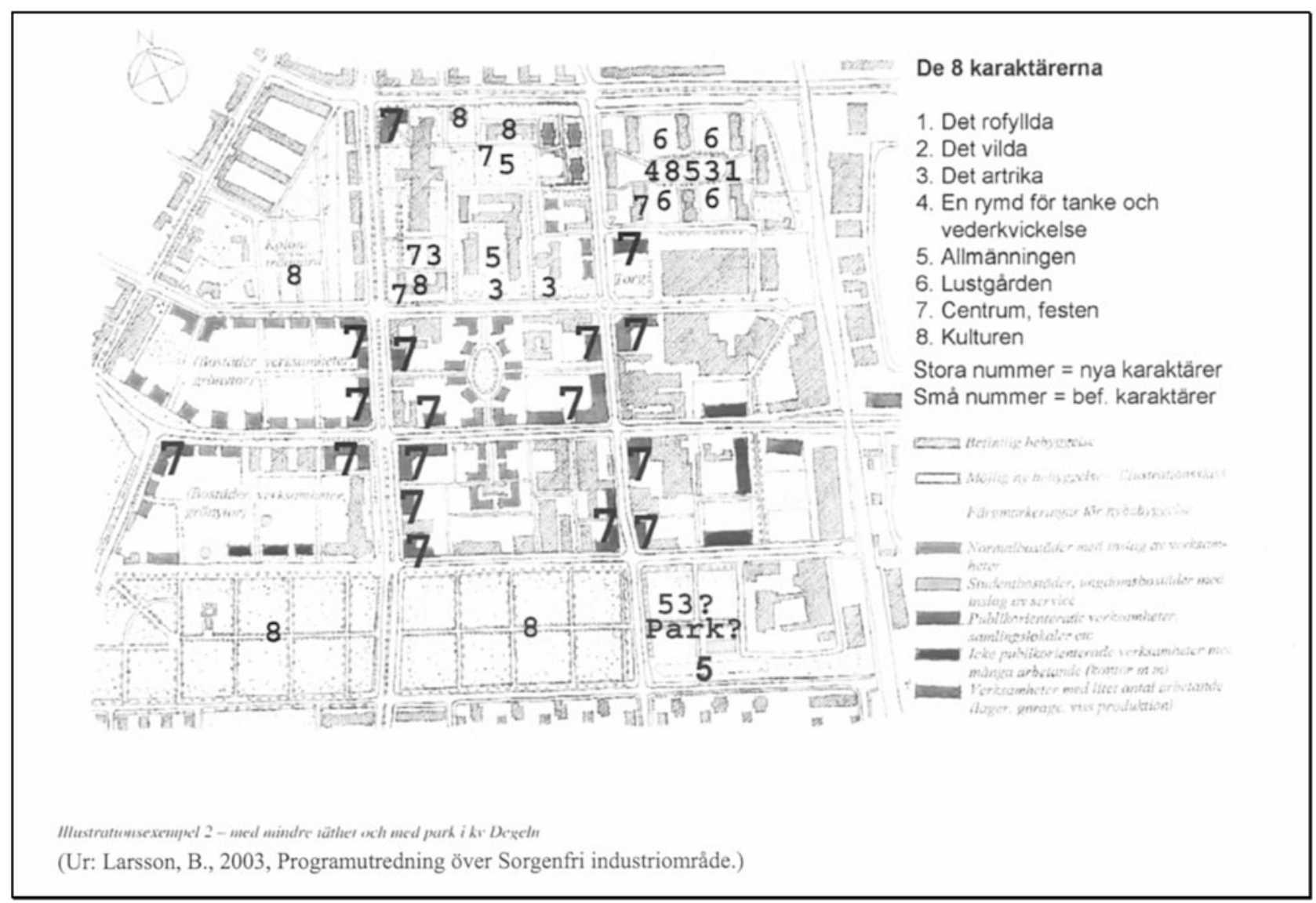

Figure 1. The recreational characteristics examined by a landscape architect (Flodmark, 2004) from an architect's (Bo Larsson) sketch, alternative 2. 
cemetery in the lower part of the picture has "Culture" values (8). The analysis shows that the architect has not provided sufficient scope for characteristics in the new blocks to be developed; however, he has included a possible park in the southeast block.

An alternative development sketch based on an analysis of the characteristics was then produced (Flodmark, 2004; see Figure 2). The attempt was to provide possibilities for many more characteristics in order to meet the needs of future inhabitants in the area. A large park occupying an entire block at the west side was suggested, in order to meet the needs of people in surrounding neighborhoods lacking open green space facilities.

Because the existing landscape resources of the industrial sites are more limited than the future demands for housing development, there is a need to define a minimum standard of biotope qualities with the application of a green factor analysis. That was done for one of the blocks, Brännaren (Jacobsson, 2004). The target for this new structure was set to a green factor of 0.6 ; this is the same target established by law for housing areas, public areas, and kindergartens in Germany. The site had no ground maintenance, the vegetation was self-sown, and the place had a rough and wild look consistent with characteristics (2) and (3). An aim was not only to reach the green area factor goal of 0.6, but also to organize the site design (see Figure 3) so that certain characteristics could be included (Jacobsson, 2004). According to the landscape architect, the area is supposed to be developed into a residential area with businesses; the site will be accessible to the public and many new characteristics will be developed. The smaller areas near the buildings have a central function and will be important meeting points; they include the "Festive/ centre" characteristic (7). The large open green area has the characteristic of "The common" (5). The smaller place in the southern part of the area is proposed to maintain the

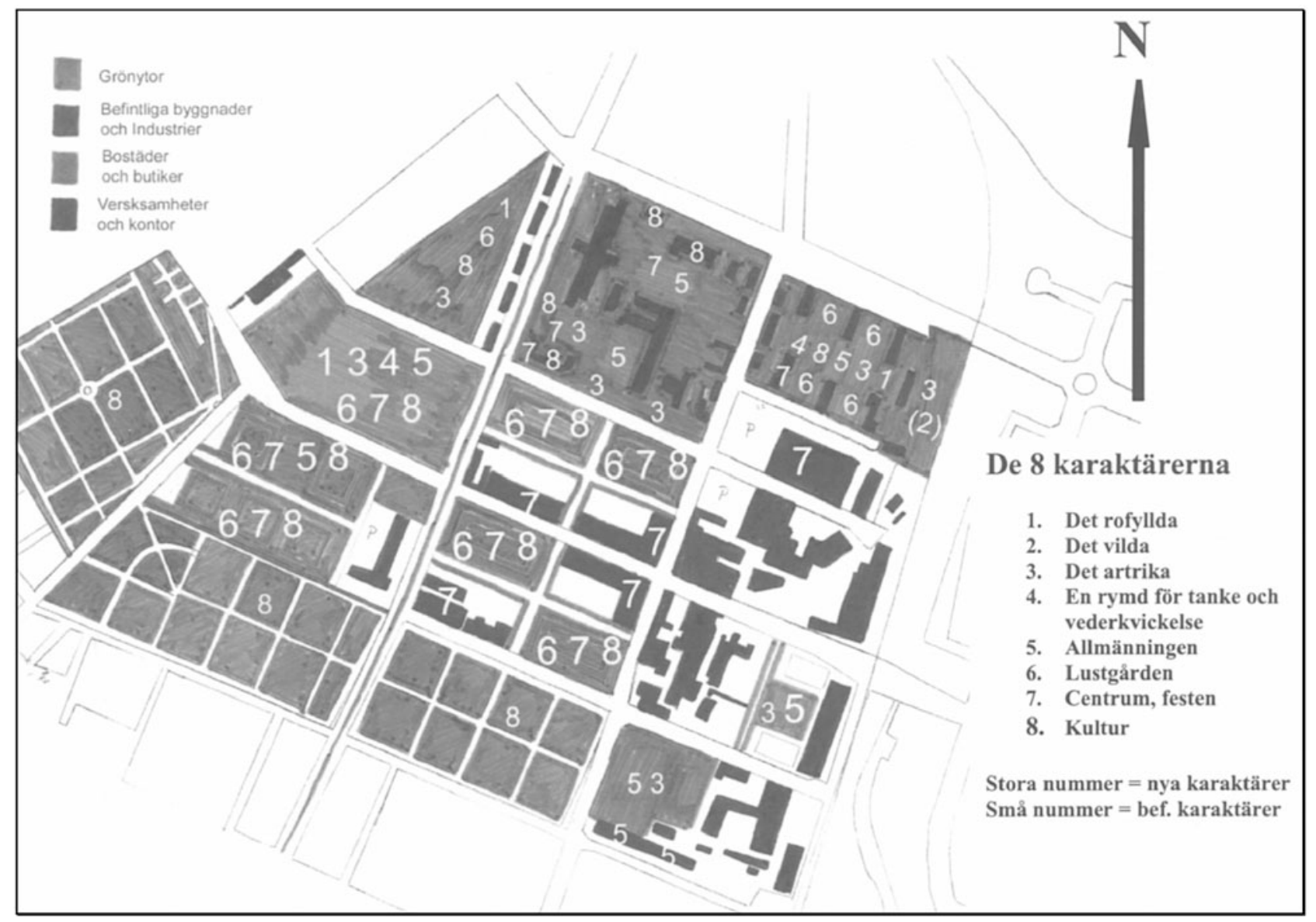

Figure 2. The recreational characteristics of a sketch by the landscape architect (Flodmark, 2004). 


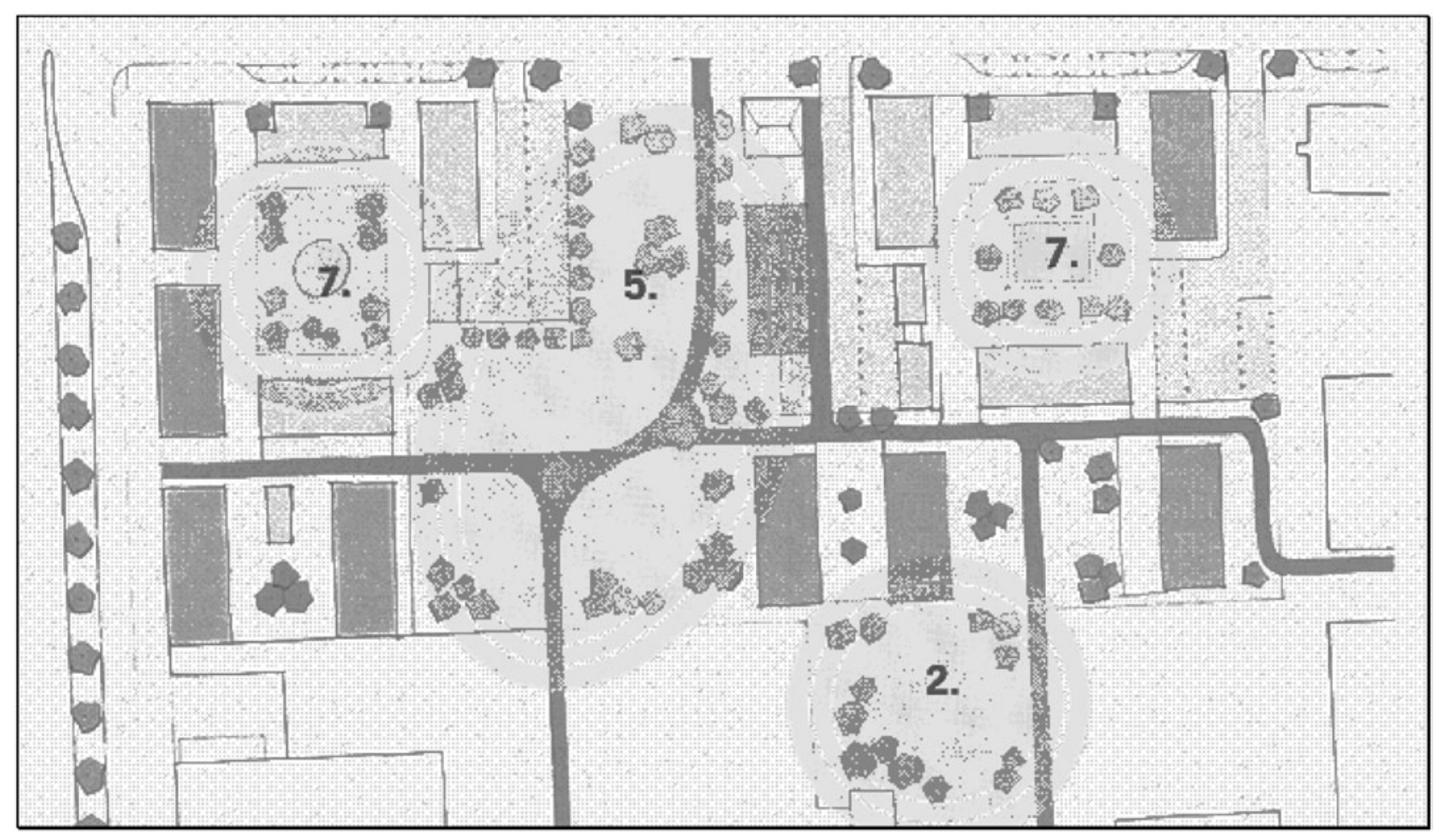

Figure 3. New recreational characteristics with the design of Karin Jacobsson (2004).

former character of the area; the "Wild" character (2) with self-sown plants and small paths could be an interesting area for children to play in.

\section{Svedala: Sturup Airport}

The Malmö-Sturup airport is situated in an expansive region with a steadily increasing population and high pressure to exploit land and expand infrastructure. The Airport Agency is investigating how two more runways could be situated across or parallel to the existing runway. The airport is situated in an area rich in recreational values, on the border between the Scandinavian forest and European plain areas. The current recreational values of the forests in Svedala municipality west of the airport are "Serene," "Spacious," and "Wild." This area is ecologically important, with a large variety of habitats acting as refuge for many rare and threatened species. Last, but not least, is the restorative function, which the area serves for people from the cities in southwest Skåne. Several parts of the area are very frequently used for recreational purposes. There is a growing awareness that areas in Skåne, where people can relax in a restorative environment, will be important assets for pro- moting a healthy lifestyle, as well as for profiling the Öresund Region as a "clean region."

Airport expansion will inevitably mean additional noise, impacting new areas and increasing the noise level in already noise-affected areas. If we focus on the characteristic "Serene," would it be possible to balance the noise and compensate for additional noise by reducing noise in other places? Probably not, but it may be possible to balance the recreational function to some extent (Skärbäck, 2007). Silent areas affected by noise from a new parallel runway may be compensated for by improving recreational qualities in silent agricultural areas that will not be affected (see Figure 4 and Table 1) and that are, thus, good candidates for compensation measures to improve recreational characteristics (Karlsson, 2004). Estimated impacts of a new runway and possible measures for mitigating and compensating are shown in Table 1.

The project is, to a high degree, an inter-municipality planning issue. This collaboration requires an extraordinary planning organization outside the traditional planning process, whereby municipalities have a kind of planning 


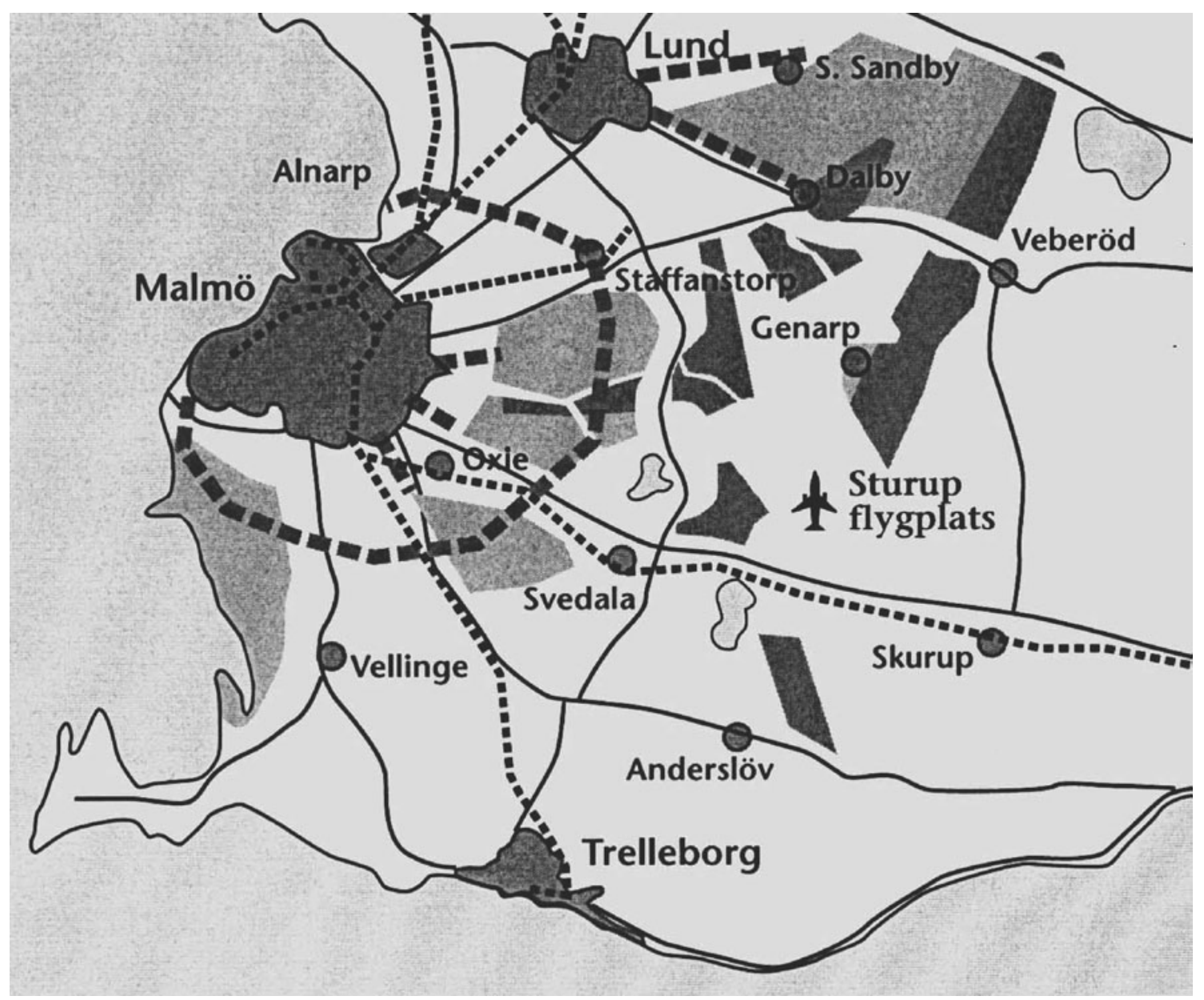

Figure 4. Dark areas: exposure to new noise as a result of an extension of Sturup airport from one to three runaways. Light areas: silent areas not affected by airplane noise and thus possible to develop for recreation as compensation for the reduction of silence in dark areas. The broad broken line: new corridors for natural elements, to improve recreational possibilities (from Karlsson, 2004).

monopoly that the Swedish government can only overturn with severe political constraints and great legal difficulty.

This airport project illustrates that compensation measures may be relevant even at a great distance from the impacted area. In the past, developers have found it troublesome and complicated to apply for compensation measures far outside their normal development site, but some need for extra administrative efforts should not stand in the way of finding and realizing good solutions. In a way, the Swedish government has invited this kind of compensation. The first environmental impact report for the bridge between Denmark and Sweden (Swedish National Environmental Protection Agency, 1978) pointed out that there would be a certain need for new recreation areas in cities surrounded by arable land and close to the bridge. This resulted in a comment from the Swedish Ministry of Communications: "The significant increase in the accessibility in the Öresund Region requires certain efforts to protect sensitive areas and to raise the capacity in other areas suitable for recreation" (Swedish Ministry of Communications, 1978).

\section{Discussion}

Both case studies have investigated the "before" and "after" situations of the eight outdoor environment characteristics shown to be associated with basic human needs for recreation and stress reduction. For each case, discussions have concerned different ways in which decline in or absence of 
Table 1. Examples of estimated impacts from a new runway on important values and functions, along with measures for mitigating and compensating for unavoidable negative impacts (Karlsson, 2004)

\begin{tabular}{|c|c|c|}
\hline Values and functions & Impacts & Measures \\
\hline $\begin{array}{l}\text { The hilly undulating } \\
\text { landscape of the area } \\
\text { is characteristic of the } \\
\text { identity of the region }\end{array}$ & $\begin{array}{l}\text { The whole of the } \\
\text { landscape will be } \\
\text { demolished }\end{array}$ & $\begin{array}{l}\text { Restore pastureland and wetlands in the surroundings. Change evergreen } \\
\text { forests to broadleaf forests and create small rivers and other elements. }\end{array}$ \\
\hline $\begin{array}{l}\text { The accessible } \\
\text { landscape, e.g. } \\
\text { hiking tracks }\end{array}$ & $\begin{array}{l}\text { A new runway will } \\
\text { be a barrier between } \\
\text { frequently used } \\
\text { recreation forests }\end{array}$ & $\begin{array}{l}\text { Extend the accessibility of half-open landscape closer to Malmö. Create green } \\
\text { links in the arable landscape with new bicycle roads and riding paths. }\end{array}$ \\
\hline $\begin{array}{l}\text { The Torup beach forest } \\
\text { west of the airport } \\
\text { (the closest forest area } \\
\text { for Malmö) }\end{array}$ & $\begin{array}{l}\text { Airplanes from the } \\
\text { crossing runway pass } \\
\text { right over: loss of } \\
\text { some silent areas }\end{array}$ & $\begin{array}{l}\text { Improve visual values. Create new trails and view-points for closer observation } \\
\text { of flora and fauna. }\end{array}$ \\
\hline $\begin{array}{l}\text { Wildlife corridor north } \\
\text { of the airport }\end{array}$ & $\begin{array}{l}\text { A new parallel runway } \\
\text { will be a barrier between } \\
\text { two large biotopes }\end{array}$ & $\begin{array}{l}\text { Improve a corridor north of the runway and creating new corridors of } \\
\text { isolated biotopes. }\end{array}$ \\
\hline $\begin{array}{l}\text { Existing noise-disturbed } \\
\text { recreation areas }\end{array}$ & Extensive noise & $\begin{array}{l}\text { Measures to reduce noise from roads and railroads. Improve the biotopes } \\
\text { for wildlife and build noise-protected shelters for studying the animals. } \\
\text { Improve visual qualities as compensation for the deteriorating sound values. }\end{array}$ \\
\hline $\begin{array}{l}\text { Silent recreation areas } \\
(<40 \mathrm{~dB})\end{array}$ & Additional noise & $\begin{array}{l}\text { Establish new recreation areas in silent areas, e.g., Käglinge-Arrie-Törringe, } \\
\text { and on the "South agricultural plain", towards Trelleborg. } \\
\text { Protect and defend silent areas. }\end{array}$ \\
\hline $\begin{array}{l}\text { Silent recreation areas } \\
(<40 \mathrm{~dB})\end{array}$ & No further noise impact & $\begin{array}{l}\text { Improve the recreational value by creating new paths and places, bicycle roads. } \\
\text { Create new dams and small streams and vegetation. Improve accessibility for } \\
\text { walking in arable land. }\end{array}$ \\
\hline $\begin{array}{l}\text { Silent areas not yet used } \\
\text { for recreation (because } \\
\text { of agriculture or distance) }\end{array}$ & No further noise impact & $\begin{array}{l}\text { Create new recreational values such as forests, meadows, wetlands and water. } \\
\text { Protect of silent areas by purchase. }\end{array}$ \\
\hline Indoor silence & $\begin{array}{l}\text { Increasing noise in Bara } \\
\text { from a crossing runway }\end{array}$ & Change to noise-reducing windows. \\
\hline
\end{tabular}

certain characteristics can be compensated for by improving existing characteristics or adding new ones. The balancing method and/or the green area factor method may be used as planning instruments in this regard (Figure 5).

In the case of Sorgenfri, the environmental characteristics prior to exploitation are generally lower than the demands made after future exploitation. The green area factor method can be used together with goals to improve certain characteristics. In the case of Sturup, today's environmental characteristics are at a high level, despite the noise loads caused by current air traffic. The planned extension of air traffic at Sturup and the new runways will diminish certain characteristics, e.g. "Serene." This can be compensated for by improving possibilities for use in existing recreational areas that will not experience noise levels over $40 \mathrm{dBA}$, even after expansion of the airport. It can also be compensated for by improving possibilities for recreation in new areas with noise levels under 40 dBA. The "Serene" characteristic can also be compensated for by improving possibilities for recreation in farming areas in the periphery of Malmö and Lund that have noise levels less than 40 dBA.

\section{Ethical Points of Departure}

The balancing principle-which requires compensation for unavoidable deterioration in an environmental function 


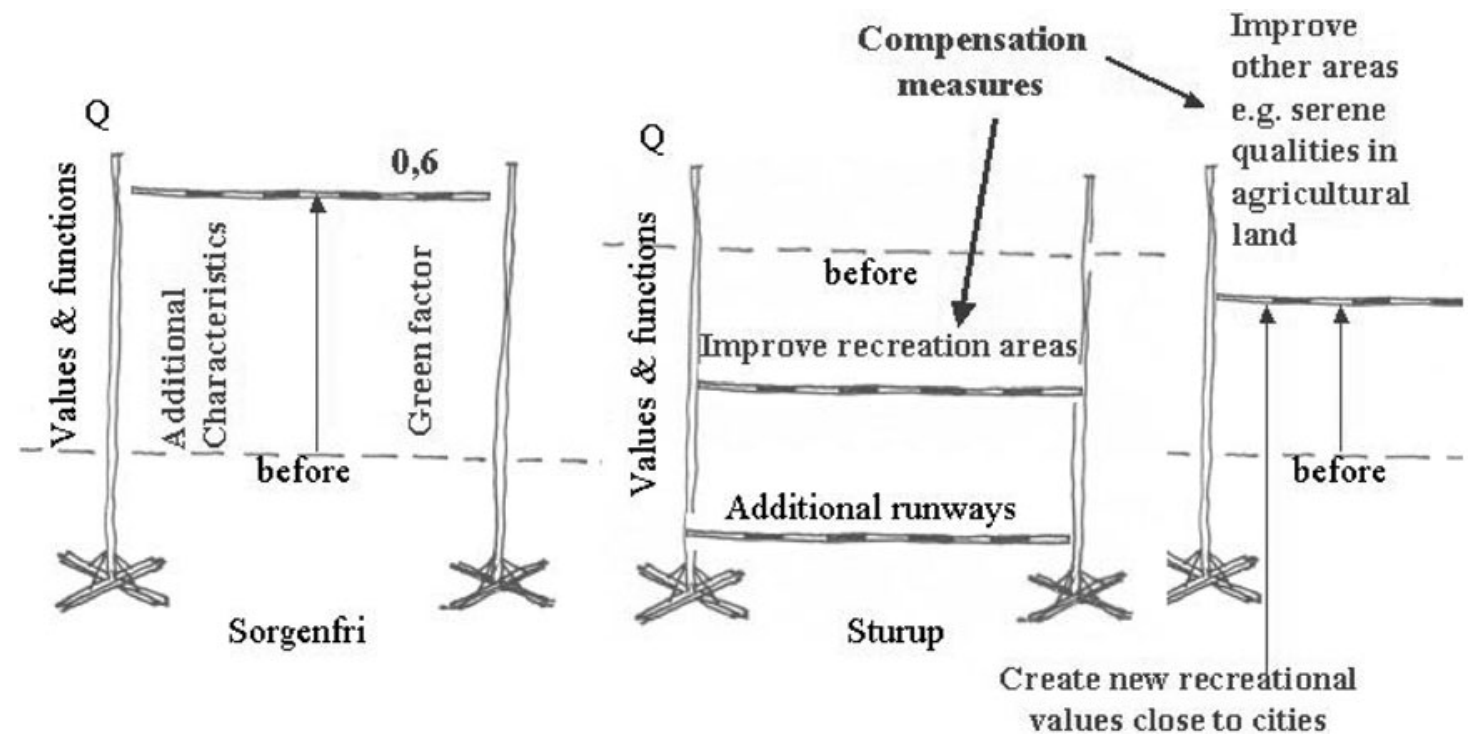

Figure 5. Sorgenfri is an example of a situation in which existing recreational qualities are low and have to be improved. The extension of Sturup airport is an example of a situation in which high recreational qualities will be destroyed. Negative impact on recreation in disturbed areas could be compensated for by improving characteristics not as sensitive to noise, and in silent agricultural farmland outside the cities, new recreational serene qualities could be created.

through improvement of the same function at another location or improvement of another function at the same location-is based on two ethical principles: (1) natural resource management, the notion that every small project must not lead to gradual deterioration of natural amenity values, but should instead create new values at the same rate as existing values are disturbed (silence is an almost irreversible resource); and (2) the ability to require of developers that they give back as much as they take and that natural amenity values not be viewed as "free commodities." In the case of Sturup, the practical implication is that the Swedish Civil Aviation Administration must cover the costs of developing new possibilities for recreation outside Malmö and Lund, because noise from the airport will be disruptive in the new recreational areas. Thus, in accordance with the "polluter pays principle," the national government will cover the costs that otherwise would have affected the municipality.

\section{Political Argumentation}

An attractive business park region can easily be overexploited and lose its appeal. The prime ministers of Sweden and Denmark, in connection with the opening of the bridge between Sweden and Denmark, have mutually expressed that the Öresund Region shall remain one of the cleanest regions in Europe. This statement from the prime ministers immediately raises the questions: What did they include in the concept "clean"? Did they only mean clean water and clean air, or even a sonic environment free from excessive noise? Did they also mean visual qualities and an aesthetically beautiful environment? These are, of course, rhetorical questions. If we were to ask the prime ministers, they would never admit that such health aspects should be excluded. By making this statement, however, they have expressed the political ambition to promote quality and environmental competitiveness at an international level, and it is up to others to work out the details. That is why those of us in the transnational research group have allowed ourselves to include recreation and health aspects in our definition of a clean Öresund environment.

The method illustrated here-of operationalizing the eight characteristics to promote health in planning and impact analysis and of analyzing possibilities to balance, compensate for, and improve characteristics through measures tied to exploitation-corresponds in all essential respects to the new EU directive (SEA, Strategic Environmental Assessment) on impact analysis for plans and programs (Economic Commission for Europe, 2003). Concerning rec- 
reational and health aspects, the present project can help to monitor the human health aspect in accordance with this EU directive.

The European Parliament (2001) states that it is important to ensure that future infrastructure projects will be better planned than today's projects, so that our children will not be drowned in noise. The EU directive aims at ensuring that environmental, including health, considerations are thoroughly taken into account in the development of plans and programs. Finally, the European Landscape Convention also states that the health functions of the landscape are very important resources: "Landscape is a key element of individual and social well-being" (Council of Europe, 2000).

\section{Acknowledgment}

I dedicate this article to my friend, Dr. Jim Roberts, Sacramento, California, who has been a mentor of mine since my PhD studies early in the 1980 os and who has occasionally taught in the Master's Program for Landscape Planners at SLU, Alnarp, Sweden.

\section{References}

Babisch, W., B. Beule, M. Schust, N. Kersten, and H. Ising. 2005. Traffic Noise and Risk of Myocardial Infarction. Epidemiology 16:33-40.

Boverket. 1994. Stadens Parker och Nature (Parks and Green Areas in the City). Rapport 1994:12, Boverket, Karlskrona.

Caspersen, O. H, C. Konijnendijk, and A. S. Olafsson. 2006. Green Planning in Long Term Perspective: The Recreational Landscape of Greater Copenhagen. Submitted to Danish Journal of Geography.

Clewell, A. F. 2000. Restoration of Natural Capital. Restoration Ecology 8(1):1.

Costanza, R., R. d'Arge, R. de Groots, S. Farber, M. Grasso, B. Hannon, K. Limburg, S. Naeem, R. V. O’Neill, J. Paruelo, R. G. Raskin, P. Sutton, and M. van den Belt. 1997. The Value of the World's Ecosystem Services and Natural Capital. Nature 387:253-60.

Council of Europe. 200o. European Landscape Convention (ELC), Council of Europe, Strasbourg, http://www.coe.int/t/e/cultural_co-operation/ environment/landscape/presentation/9_text/o2_Convention_EN.asp\# TopOfPage.

Cross, R. G. 1991. Evolutionary Persistence of Memory-Like Processes. In Concepts in Neuroscience, volume 2, 129-168.

Economic Commission for Europe. 2003. Protocol on Strategic Environmental Assessment to the Convention on Environmental Impact Assessment in a Transboundary Context. ECE/MP.EIA/2003/3.

European Parliament. 2001. Europaparlamentets och rådets direktiv 2001/ 42/EG av den 27 juni 2001 om bedömning av vissa planer och programs miljöpåverkan. Europeiska gemenskapernas officiella tidning, L 197/30,
21.7.2001. (Protocol on Strategic Environmental Assessment to the Convention on Environmental Impact Assessment in a Transboundary Context.)

Flodmark, S. 2004. Sorgenfri Industrial Area: An Analysis of Spatial and Landscape Qualities (Sorgenfri Industriområde: En Analys av Områdets Kvaliteter i Form av Rumskaraktärer), Stadsbyggnadskontoret, Malmö.

Grahn, P., and U. Stigsdotter. 2003. Landscape Planning and Stress. Urban Forestry \& Urban Greening, volume 2, Urban \& Fischer Verlag, Jena, 1-18.

Grahn, P., U. Stigsdotter, and A.-M. Berggren-Bärring. 2005a. A Planning Tool for Designing Sustainable and Healthy Cities: The Importance of Experienced Characteristics in Urban Green Open Spaces for People's Health and Well-Being. In conference proceedings, "Quality and Significance of Green Urban Areas," April 14-15, Van Hall Larenstein University of Professional Education, Velp, The Netherlands.

Grahn, P., U. Stigsdotter, and A.-M. Berggren-Bärring. 2005b. Human Issues: Eight Experienced Qualities in Urban Open Spaces. Green Structure and Urban Planning Final Report of COST Action C11, Luxembourg: Office for Official Publications of the European Communities 2005:240-8.

Hartig, T. 1993. Testing Restorative Environments Theory. Doctoral Dissertation. University of California, Irvine.

Hartig, T., A. Böök, J. Garvill, T. Olsson, and T. Gärling. 1996. Environmental Influences on Psychological Restoration. Scandinavian Journal of Psychology 37:378-393.

Hedfors, P. 2003. Site Soundscapes: Landscape Architecture in the Light of Sound. Agria 407, Swedish University of Agricultural Sciences, Alnarp.

Jacobsson, K. 2004. Sorgenfri Industrial Area. From the course, "EIR and Landscape Balancing in Large Projects," Department of Landscape Planning, Swedish University of Agricultural Sciences, Alnarp, http://kurs.slu.se/ kurser/LP0358/10086.0405/RapportA4.pdf.

Kaplan, R., and S. Kaplan. 1989. The Experience of Nature. Cambridge University Press, Cambridge, UK.

Kaplan, S. 1990. Parks for the Future: A Psychological Perspective. In Parks for the Future, G. Sorte, ed. Stad \& Land 85, Alnarp, 4-22.

Kaplan, R., S. Kaplan, and R. L. Ryan. 1998. With People in Mind. Island Press, Washington, DC.

Karlsson, L. 2004. Sturup Airport. From the course, "EIR and Landscape Balancing in Large Projects," Department of Landscape Planning, Swedish University of Agricultural Sciences, Alnarp, http://kurs.slu.se/kurser/ LP0358/10086.0405/Lindas_rapport_pdf.pdf.

Nilsson, K., C. Konijnendijk, and T. B. Randrup. 1999. Urban Forestry: Where People Meet Trees. In Community Forestry: A Change for the Better. Conference proceedings, Forest for the Community, Forestry Commission and the Countryside Agency, December 7-8, London, 28-31.

Östlund, N. 2006. Mapping Your Community: A Swedish Case Study on Communication of Landscape Qualities on the Internet and Attitudes towards Public Participation. Urisa Proceedings, Urisa Annual Conference, September 26-29, Vancouver, BC, Canada.

Ottosson, J., and P. Grahn. 1998. Utemiljöns Betydelse för Äldre med Stort Vårdbehov. Licentiatavhandling för J. Ottosson, Stad \& Land 155, Alnarp.

Ottosson, J., and P. Grahn. 2005a. A Comparison of Leisure Time Spent in a Garden with Leisure Time Spent Indoors: On Measures of Restoration in Residents in Geriatric Care. Landscape Research 30:23-55.

Ottosson, J., and P. Grahn. 2005b. Measures of Restoration in Geriatric Care Residences. Journal of Housing for the Elderly 19(3/4):229-258. 
Ottosson, J., and P. Grahn. 2006. The Role of Nature in People's Rehabilitation from Crises: How Does the Level of Crisis Influence the Response to Experiences of Nature with Regard to Measures of Rehabilitation? Submitted to Conceptual and Empirical Development.

Parsons, R., L. G. Tassinary, R. Ulrich, M. Hebl, and M. GrossmanAlexander. 1998. The View from the Road: Implications for Stress Recovery and Immunization. Journal of Environmental Psychology 18:113-140.

Rundcrantz, K. 2006. Environmental Compensation in Swedish Road Planning. European Environment 16:350-367. (Also online at Wiley InterScience.)

Rundcrantz, K., and E. Skärbäck. 2003. Environmental Compensation in Planning: A Review of Five Different Countries with Major Emphasis on the German System. European Environment. 13:204-226.

Scott, K. I., E. G. McPherson, and J. R. Simpson. 1998. Air Pollutant Uptake by Sacramento's Urban Forest. Journal of Arboriculture 24(4): 224-234.

Searles, H. F. 1960. The Nonhuman Environment in Normal Development and in Schizophrenia. International Universities Press, New York.

Skärbäck, E. 1997. Is the Method of Balancing a Potential Tool for the Protection and Rehabilitation of Landscape? A Comparison of Eastern Germany and Southern Sweden. Paper and presentation at conference, Urban, Regional, Environmental Planning and Informatics to Planning in an Era of Transition, October 22-24, Technical University, Athens.

Skärbäck, E. 2007. Urban Forests as Compensation Measures for Infrastructure Development. Accepted for publication in Journal of Urban Forestry \& Urban Greening, Elsevier.
Stigsdotter, U. 2005a. Urban Green Spaces: Promoting Health through City Planning: Inspiring Global Environmental Standards and Ethical Practices. The National Association of Environmental Professionals' 3oth Annual Conference, April 16-19, Alexandria, VA; conference proceedings, Ur Landscape Architecture and Health, Doctoral Thesis, No. 2005:55, Swedish University of Agricultural Sciences, Alnarp.

Stigsdotter, U. 2005b. Landscape Architecture and Health: Evidence Based Health Promoting Design and Planning. Doctoral Thesis ACTA, No. 2005:55, Swedish University of Agricultural Sciences, Alnarp.

Stigsdotter, U., and P. Grahn. 2002. What Makes a Garden a Healing Garden? Journal of Therapeutic Horticulture 13:60-69.

Swedish Ministry of Communications. 1978. 1978:18, Öresundsförbindelser, Ministry of Communications, Stockholm.

Swedish National Environmental Protection Agency. 1978. Öresundsförbindelser Landskapsanalys, Delutredning Utförd för den Svenska Öresundsdelegationens Expertgrupp för Plan och Miljöfrågor. Statens Naturvårdsverk, Meddelande 3/78.

Ulrich, R. S. 1993. Biophilia, Biophobia, and Natural Landscapes. In The Biophilia Hypothesis, S. R. Kellert and E. O. Wilson, eds. Island Press, Washington, DC, 73-137.

Ulrich, R. S., R. F. Simons, B. D. Losito, E. Fiorito, M. A. Miles, and M. Zelson. 1991. Stress Recovery during Exposure to Natural and Urban Environments. Journal of Environmental Psychology 11:201-230.

Submitted April 11, 2006; revised September 15, 2007; accepted September 19, 2007 . 